\title{
Predictors of outcome and different management of aortobronchial and aortoesophageal fistulas
}

\author{
Victor X. Mosquera, MD, PhD, ${ }^{a}$ Milagros Marini, MD, PhD, ${ }^{b}$ Francisco Pombo-Felipe, MD, PhD, \\ Pablo Gómez-Martinez, MD, ${ }^{b}$ Carlos Velasco, MD, ${ }^{a}$ José M. Herrera-Noreña, MD, PhD, ${ }^{a}$ and \\ José J. Cuenca-Castillo, MD ${ }^{\mathrm{a}}$
}

\begin{abstract}
Objective: Aortoesophageal and aortobronchial fistulas are uncommon but life-threatening conditions. The present study aimed to identify potential differences in outcomes, depending on the etiology, type, and management of the fistulas, and to determine mortality predictors.
\end{abstract}

\begin{abstract}
Methods: We retrospectively reviewed a series of 26 consecutive patients with thoracic aorta fistulas admitted to our institution from 1998 to 2013 (18 aortobronchial, 7 aortoesophageal, and 1 combined fistula).

Results: The mean age was $61.5 \pm 13.4$ years, with 22 men. Management was thoracic endovascular aortic repair (TEVAR) in 8 , open repair in 7 , and conservative in 11 . The TEVAR and nonoperative patients were significantly older and presented with more comorbidities. Shock developed in 15 patients and sepsis in 9. The most common radiologic findings were intramural hematoma $(65.4 \%)$, pseudoaneurysm $(53.8 \%)$, and bronchial compression (46.20\%). Active contrast extravasation (23.1\%) and ectopic gas $(19.2 \%)$ were associated with a worse prognosis. In-hospital mortality was $100 \%$ in the conservative group, $37.5 \%$ in the TEVAR group, and $14.3 \%$ in the open repair group $(P=.04)$. Septic shock was the most common cause of death. The risk factors for in-hospital mortality were hemodynamic instability on admission $(P=.02)$, sepsis $(P=.04)$, and conservative management $(P<.001)$. The overall long-term survival in surgical patients at 1 and 5 years was $66 \%$ and $58.7 \%$, respectively. Infectious and malignant etiologies resulted in the worst prognosis.
\end{abstract}

Conclusions: The outcomes are ultimately conditioned by the etiology of the fistula. Both open and endovascular management of aortic fistulas can prevent death by exsanguination; however, patients remain at high risk of infectious complications. Failure to treat the underlying cause will result in poor midterm outcomes. (J Thorac Cardiovasc Surg 2014;148:3020-6)

Supplemental material is available online.

Aortoesophageal (AEF) and aortobronchial (ABF) fistulas pose one of the most vexing and challenging surgical problems to manage. Both types of thoracic aorta fistulas are uncommon, but life-threatening conditions if left untreated. Primary AEFs and ABFs are most commonly found in association with aortic aneurysms, ruptured penetrating aortic ulcers, thoracic trauma, ingestion of foreign bodies, and esophageal or bronchogenic malignancies. Secondary fistulas are potential complications of either open ${ }^{1}$ or endovascular thoracic aorta surgery. ${ }^{2-4}$

From the Departments of Cardiac Surgery ${ }^{\mathrm{a}}$ and Radiology, ${ }^{\mathrm{b}}$ Complejo Hospitalario Universitario de A Coruña, A Coruña, Spain

Disclosures: Authors have nothing to disclose with regard to commercial support.

Received for publication Feb 8, 2014; revisions received April 14, 2014; accepted for publication May 16, 2014; available ahead of print June 26, 2014.

Address for reprints: Victor X. Mosquera, MD, PhD, Department of Cardiac Surgery, Complejo Hospitalario Universitario de A Coruña, As Xubias no 84, A Coruña CP 15006, Spain (E-mail: Victor.X.Mosquera.Rodriguez@sergas.es).

$0022-5223 / \$ 36.00$

Copyright (C) 2014 by The American Association for Thoracic Surgery

http://dx.doi.org/10.1016/j.jtcvs.2014.05.038
The classic management of ABFs and AEFs has been open surgical repair. Nonetheless, single center series ${ }^{5-7}$ and multicenter studies ${ }^{8,9}$ describing the successful management of both AEFs and ABFs using thoracic endovascular aortic repair (TEVAR) have been published during the past 10 years. Both open and endovascular surgical treatment can prevent patient death by exsanguination; however, patients remain at high risk of infectious complications. Neither the bronchi nor the esophagus are sterile cavities; therefore, the risk of infectious complications is significantly increased if the bronchial or esophageal defect is not repaired. This is of utmost importance when managing aortic fistulas caused by mycotic pseudoaneurysms or malignancy. Furthermore, addressing the underlying pathologic entity is crucial when considering the mid- and long-term outcomes of the fistulas.

The aim of the present study was to identify potential differences in early- and long-term results, stratified by the etiology, type, and management of the fistulas, and to determine the mortality predictors in this critical subset of patients. We also report the clinical and radiologic characteristics, treatment, and outcomes of a consistent series of patients with AEFs and ABFs. 


\section{Abbreviations and Acronyms}

$\mathrm{ABF}=$ aortobronchial fistula

$\mathrm{AEF}=$ aortoesophageal fistula

$\mathrm{CT}=$ computed tomography

TEVAR $=$ thoracic endovascular aortic repair

\section{METHODS}

This was an historic cohort study enrolling a total of 26 patients with thoracic aorta fistulas admitted to our institution from January 1998 to October 2013. The thoracic aorta fistulas involved the left bronchial tree in 18 patients and the esophagus in 8 , including 1 patient with a combined $\mathrm{AEF}$ and $\mathrm{ABF}$.

Hemodynamic instability on admission was defined as a systolic blood pressure of $<90 \mathrm{~mm} \mathrm{Hg}$ or the need for fluid and/or inotropic support to maintain a blood pressure of $\geq 90 \mathrm{~mm} \mathrm{Hg}$.

Urgency of the surgical procedure was classified as elective, when performed during a routine admission for surgery; urgent for patients not electively admitted for surgery but who required surgery on that admission for medical reasons; and emergency, when surgery was performed before the beginning of the next working day after a decision had been made to operate.

The study adhered to the STrengthening the Reporting of OBservational studies in Epidemiology (STROBE) initiative. ${ }^{10}$ The institutional review board approved the present study for retrospective data retrieval, waiving the requirement for individual patient consent.

\section{Imaging Evaluation}

All the patients, except for 1 , had $\geq 1$ computed tomography (CT) scan performed at admission. The diagnosis was determined from the CT scan data but also using the findings from other imaging techniques (eg, angiography, transesophageal echocardiography, and gastrointestinal or bronchial endoscopy). When available, confirmation was provided by surgical visualization and/or autopsy. No disagreement was found in the data provided by the imaging studies.

The identification of active extravasation was defined as the only definitive CT scan finding of ABF or AEF. Secondary signs helped us predict the high likelihood of the diagnosis. However, they could also be seen in the presence of graft infection or inflammation without ABF or AEF. These signs included the presence of periaortic (ectopic) gas, an aortic pseudoaneurysm bulge, a penetrating atherosclerotic ulcer, an intramural hematoma, effacement of the periaortic or perigraft fat plane, esophageal wall thickening, and a periprosthetic collection. ${ }^{11-14}$

\section{Surgical Treatment}

In our series, open surgical management was selected for 7 patients. A left posterolateral thoracotomy was performed in 5 and a thoracoabdominal approach was required in 2 patients. Five patients underwent emergency open surgical repair and two underwent urgent open repair.

A Dacron graft was used in 5 patients, and patch repair was performed in 2 patients. Left heart bypass was established in 5 patients, and cardiopulmonary bypass was selected for 2 patients. Surgical repair of the bronchopulmonary end consisted of primary closure $(n=4)$ or lobectomy $(n=2)$. In 1 case of $\mathrm{AEF}$, the esophageal opening was repaired by primary closure and was reinforced with a pericardial patch.

Direct contact between the vascular reconstruction and the pulmonary or esophageal tissue was avoided to prevent additional erosive damage. The repaired aorta was covered by the remains of either the pseudoaneurysm wall $(n=3)$ or the surrounding viable tissue $(n=4)$.

Eight patients underwent TEVAR. Four TEVAR procedures were performed on an emergency basis, and four on an urgent basis. Endovascular stent placement procedures were performed in the operating room with the patients under general anesthesia. ${ }^{15}$ Access was by way of the right common femoral artery for all patients. Endovascular repair was performed using the Talent thoracic stent-graft in 1 patient, the Valiant thoracic stent-graft in 2 patients, and the Valiant Captivia thoracic stent-graft (Medtronic, Medtronic Vascular, Santa Rosa, Calif) in 5 patients. Two or more stent-grafts were used to cover the lesion in 5 patients. No patient required covering of the left subclavian artery. Adjunctive surgical procedures to TEVAR in those with an ABF were 2 left lobectomies, 3 thoracic drainage procedures, 1 bronchial stenting, and 1 surgery of a septic spondylodiscitis. In the 2 cases of AEF, 1 patient also underwent esophagectomy and cervical esophagostomy and had a feeding gastrostomy tube place, and the other patient underwent esophagectomy with reconstruction 1 week later.

The selection criteria were hemodynamic stability, comorbidities affecting the patient's life expectancy and quality of life, and factors determining technical feasibility (Online Data Supplement, "Selection Criteria"). Emergency TEVAR has been available at our institution since January 2003 because of the need for an in-hospital stock of thoracic aortic endografts (Figure E1 shows the modifications in patient management since the incorporation of emergency TEVAR).

\section{Statistical Analysis}

Data are expressed as the mean \pm standard deviation or median and range, as appropriate. ${ }^{16}$ For bivariate analysis, proportions were compared using contingency tables and the chi-square test with Yates' correction or Fisher's exact test. Student's $t$ test was used to compare continuous variables. Actuarial estimates of survival were accomplished using KaplanMeier methods. Differences in survival between the groups were analyzed using the log-rank test.

The Statistical Program for Social Sciences, for Windows, version 17.0 (SPSS, Chicago, Ill), was used for data analysis.

\section{RESULTS}

Most of the patients were men (22 patients, $84.6 \%$ ), with a mean age of $61.5 \pm 13.4$ years. The patients' demographics and preoperative risk factors are listed in Table 1.

Overall, the most common cause of the aortic fistulas was aortic atherosclerotic aneurysms ( 8 patients, $30.8 \%$ ). In those with $\mathrm{ABFs}$, aortic aneurysms remained the most common cause (6 patients, $33.3 \%$ ); however, esophageal malignancy ( 3 patients, $37.5 \%$ ) was the most common cause of AEFs.

The mean aortic diameter was $68.4 \pm 19.4 \mathrm{~mm}$ (range, 32-100). No significant differences were found between $\mathrm{ABFs}$ and AEFs in the mean aortic diameter $(69.5 \pm 18.3$ $\mathrm{mm}$ vs $65.9 \pm 22.7 \mathrm{~mm} ; P=.67)$. The thoracic descending aorta was the most commonly affected aortic segment (22 cases, $84.6 \%$ ), with the disease extending from the aortic arch in only 2 . The aortic disease was limited to the aortic arch in 4 patients $(15.3 \%)$, and the extension of the aortic disease included the abdominal aorta in 5 patients $(19.2 \%)$.

The symptoms at presentation are listed in Table 2. Of the 26 patients, $21(80.8 \%)$ had experienced progressive hemoptysis and/or hematemesis, and $15(57.7 \%)$ had presented with hemodynamic instability on arrival at the hospital or had developed it shortly after admission. Shock was present in 10 patients $(55.6 \%)$ with an $\mathrm{ABF}$ and in 5 patients $(62.5 \%)$ with an $\operatorname{AEF}(P=.74)$. The blood cultures were positive in 9 cases $(34.6 \%)$ on admission. Isolated 
TABLE 1. Demographics and preoperative risk factors

\begin{tabular}{|c|c|c|c|c|}
\hline Characteristic & Overall & $\mathbf{A B F}$ & AEF & $P$ value \\
\hline Age (y) & $61.5 \pm 13.4$ & $59.4 \pm 15.3$ & $66.2 \pm 6.6$ & .23 \\
\hline Male gender & $22(84.6)$ & $16(88.9)$ & $6(75)$ & .75 \\
\hline Obesity & $7(26.9)$ & $5(27.8)$ & $2(25)$ & .88 \\
\hline Hypertension & $17(65.4)$ & $12(66.7)$ & $6(62.5)$ & .84 \\
\hline Diabetes mellitus & $3(11.5)$ & $1(5.6)$ & $2(25)$ & .44 \\
\hline Hypercholesterolemia & $9(34.6)$ & $6(33.3)$ & $3(37.5)$ & .84 \\
\hline COPD & $11(42.3)$ & $7(38.9)$ & $4(50)$ & .6 \\
\hline Renal failure & 7 (26.9) & $4(22.2)$ & $3(37.5)$ & .42 \\
\hline Peripheral arterial disease & $9(34.6)$ & $5(27.8)$ & $4(50)$ & .27 \\
\hline Coronary artery disease & $5(19.2)$ & $2(11.1)$ & $3(37.5)$ & .3 \\
\hline Cerebrovascular disease & $2(7.7)$ & $2(11.1)$ & 0 & .85 \\
\hline Previous cardiac surgery & $10(38.5)$ & $8(44.4)$ & $2(25)$ & .34 \\
\hline Previous vascular surgery & 7 (26.9) & $4(22.2)$ & $3(37.5)$ & .42 \\
\hline ASA class $\geq$ III & $26(100)$ & $18(100)$ & $8(100)$ & .99 \\
\hline Logistic EuroSCORE (\%) & $40.7 \pm 20.4$ & $37.6 \pm 19.8$ & $47.7 \pm 21.2$ & .25 \\
\hline Primary fistula & $18(69.2)$ & $12(66.7)$ & $6(75)$ & .67 \\
\hline Etiology of fistula & & & & .13 \\
\hline Atherosclerotic aneurysm & $8(30.8)$ & $6(33.3)$ & $2(25)$ & \\
\hline Mycotic pseudoaneurysm & $3(11.5)$ & $3(16.6)$ & 0 & \\
\hline $\begin{array}{l}\text { Post-traumatic } \\
\text { pseudoaneurysm }\end{array}$ & $3(11.5)$ & $2(11.1)$ & $1(12.5)$ & \\
\hline Esophageal cancer & $3(11.5)$ & 0 & $3(37.5)$ & \\
\hline Lung cancer & $1(3.8)$ & $1(5.6)$ & 0 & \\
\hline Secondary aortic open repair & $6(23.1)$ & $5(27.8)$ & $1(12.5)$ & \\
\hline Secondary TEVAR & $2(7.7)$ & $1(5.6)$ & $1(12.5)$ & \\
\hline
\end{tabular}

Data presented as mean \pm standard deviation or $\mathrm{n}(\%) . A B F$, Aortobronchial fistula; $A E F$, aortoesophageal fistula; $C O P D$, chronic obstructive pulmonary disease; $A S A$, American Society of Anesthesiologists; TEVAR, thoracic endovascular aortic repair.

microorganisms and antibiotic therapy are listed in Table E1. Sepsis tended to be more frequent among patients with secondary fistulas, but this difference did not reach statistical significance ( $50 \%$ vs $27.8 \%, P=.27$ ). No statistically significant differences were found between those with an ABF and those with an AEF (33.3\% vs 37.5\%, $P=.99)$. The patients with sepsis experienced greater inhospital mortality $(53.3 \%$ vs $9.1 \%, P=.04)$.

TABLE 2. Symptoms at presentation

\begin{tabular}{lcclc}
\hline \multicolumn{1}{c}{ Characteristic } & Overall (n) & ABF (n) & AEF (n) & $\boldsymbol{P}$ value \\
\hline $\begin{array}{l}\text { Symptoms at presentation } \\
\quad \text { Hematemesis or }\end{array}$ & $26(100)$ & $18(100)$ & $8(100)$ & .99 \\
$\quad$ hemoptysis & & & & \\
Hemothorax & $10(38.5)$ & $7(38.9)$ & $3(37.5)$ & .99 \\
Fever & $10(38.5)$ & $7(38.9)$ & $3(37.5)$ & .94 \\
Shock & $15(57.7)$ & $10(55.6)$ & $5(62.5)$ & .74 \\
Thoracic or back pain & $17(70.8)$ & $11(68.8)$ & $6(75)$ & .99 \\
Abdominal pain & $3(12.5)$ & 0 & $3(37.5)$ & .03 \\
Dyspnea & $7(26.9)$ & $4(22.2)$ & $3(37.5)$ & .41 \\
Dysphagia & $8(30.8)$ & $3(16.7)$ & $5(62.5)$ & .06 \\
Melena & $2(7.7)$ & 0 & $2(25)$ & .16 \\
Malaise or weight loss & $10(38.5)$ & $7(38.9)$ & $3(37.5)$ & .99 \\
Chronic anemia & $6(23.1)$ & $3(16.7)$ & $3(37.5)$ & .51 \\
\hline
\end{tabular}

Data in parentheses are percentages. $A B F$, Aortobronchial fistula; $A E F$, aortoesophageal fistula.
The diagnostic test and CT scan findings are listed in Table 3. The most common CT findings were, in descending order of frequency, hemorrhage of the aortic wall or intramural hematoma (17 patients, $65.4 \%$ ), aortic pseudoaneurysm bulge (14 patients, 53.8\%), and bronchial compression (12 patients, 46.20\%). Although bronchial compression was more frequent in those with $\mathrm{ABFs}$, this finding also appeared in some patients with an AEF without an $\mathrm{ABF}(50 \%$ vs $37.5 \%, P=.88$ ).

Both active contrast extravasation and the ectopic gas were present exclusively in those with AEFs. The identification of active contrast extravasation was an ominous sign for prognosis, with greater in-hospital mortality, but the difference did not reach statistical significance $(33.3 \%$ vs $9.1 \%, P=.32)$. In contrast, the presence of periaortic or ectopic gas was associated with in-hospital mortality $(33.3 \%$ vs $0 \%, P=.04)$.

Eleven patients $(42.3 \%)$ did not undergo any surgical (open or endovascular) treatment (6 with an $\mathrm{ABF}$ and 5 with an AEF). Nine patients were deemed not to be surgical candidates, for either open or endovascular repair, because of advanced malignancy, advanced age, and/or other severe premorbid conditions. These patients' life expectancy and quality of life were so severely impaired by their associated comorbidities that a conservative approach was selected. The mean logistic EuroSCORE in this group of 9 patients 
TABLE 3. Diagnostic test and CT scan findings

\begin{tabular}{|c|c|c|c|c|}
\hline Characteristic & $\begin{array}{c}\text { Overall } \\
\text { (n) }\end{array}$ & $\begin{array}{c}\mathbf{A B F} \\
(\mathbf{n})\end{array}$ & $\begin{array}{c}\text { AEF } \\
(\mathbf{n})\end{array}$ & $P$ value \\
\hline \multicolumn{5}{|l|}{ Diagnostic studies } \\
\hline CT scan & $25(96.2)$ & 17 (94.4) & $8(100)$ & .99 \\
\hline MDCT scan & $18(69.2)$ & $10(55.6)$ & $8(100)$ & .03 \\
\hline Aortography & $12(46.2)$ & $7(38.9)$ & $5(62.5)$ & .49 \\
\hline $\begin{array}{l}\text { Gastrointestinal or } \\
\text { bronchial endoscopy }\end{array}$ & $9(34.6)$ & $4(22.2)$ & $5(62.5)$ & .07 \\
\hline TEE & $10(38.5)$ & $7(38.9)$ & $3(37.5)$ & .99 \\
\hline \multicolumn{5}{|l|}{ CT findings } \\
\hline Active extravasation & $6(23.1)$ & 0 & $6(75)$ & $<.001$ \\
\hline Periaortic gas & $5(19.2)$ & 0 & $5(62.5)$ & .001 \\
\hline Pseudoaneurysm bulge & $14(53.8)$ & $10(55.6)$ & $4(50)$ & .99 \\
\hline Penetrating aortic ulcer & $9(34.6)$ & 7 (38.9) & $2(25)$ & .49 \\
\hline Intramural hematoma & $17(65.4)$ & $11(61.1)$ & $6(75)$ & .81 \\
\hline $\begin{array}{l}\text { Effacement of periaortic } \\
\text { or perigraft fat plane }\end{array}$ & $8(30.8)$ & $1(5.6)$ & $7(87.5)$ & $<.001$ \\
\hline Esophagus wall thickening & $4(15.4)$ & 0 & $4(50)$ & .005 \\
\hline Periprosthetic collection & $4(15.4)$ & $2(11.1)$ & $2(25)$ & .75 \\
\hline Bronchial compression & $12(46.2)$ & $9(50)$ & $3(37.5)$ & .55 \\
\hline
\end{tabular}

was $54.4 \% \pm 13.9 \%$. Of the 11 patients who did not undergo surgery, 2 patients had been deemed surgical candidates but died shortly before the surgery: a 21year-old man with a post-traumatic pseudoaneurysm and an $\mathrm{ABF}$ who died of massive hemoptysis despite advanced resuscitation techniques when being transferred to the operating room and a 72-year-old woman with a large thoracic aorta aneurysm and an AEF who died of a massive hematemesis while waiting the arrival of a suitable thoracic aortic endograft.

Fifteen patients $(57.7 \%)$ underwent surgery (12 with ABFs and 3 with AEFs). Of the 15 patients, 7 underwent open surgery and 8 underwent TEVAR. The patients undergoing TEVAR were significantly older than those undergoing open repair $(65.2 \pm 6.4$ years vs $51.7 \pm 11.5$ years, $P=.01$ ). All the patients who underwent TEVAR, except for 1 , had been excluded from open repair because of prohibitive comorbidities. Only the TEVAR group included aortic fistulas caused by infection or malignancy. The TEVAR patients presented with a higher mean logistic EuroSCORE than the open surgery patients; however, this difference did not reach statistical significance $(33.6 \% \pm$ $20.4 \%$ vs $29.5 \% \pm 20.2 \%, P=.7)$.

In the patient with a simultaneous $\mathrm{ABF}$ and AEF, TEVAR and bronchial stenting were used as a planned bridge to definitive open repair. However, the patient died 5 days later of septic shock before the open surgery stage of treatment.

The overall mean interval from diagnosis to surgery was $5.3 \pm 4.9$ days.

Complications after open surgical repair occurred in 2 patients: paraparesis with subsequent complete recovery in 1 and wound infection in 1. In the TEVAR group, 3 complications occurred: catheter-related bacteremia in 1, respiratory infection in 1 , and fatal stroke (cause of death) in 1 patient.

All patients conservatively treated died during hospital admission. In contrast, in-hospital mortality was $26.7 \%$ in the surgical group $(P<.001)$. Surgical operative deaths occurred in 3 cases $(37.5 \%)$ in the TEVAR group and 1 case $(14.3 \%)$ in the open repair group. These 4 operative deaths were caused by septic shock in 2 patients with $\mathrm{ABF}$ and 1 patient with simultaneous $\mathrm{AEF}$ and $\mathrm{ABF}$ and by atheroembolic stroke in 1 patient with $\mathrm{ABF}$.

The overall in-hospital mortality was $57.7 \%(\mathrm{n}=15)$. The overall mean expected in-hospital mortality predicted by the logistic EuroSCORE was $43.6 \% \pm 19.4 \%$. The inhospital cause of death was septic shock in 7 patients, hemorrhagic shock in 5, and multisystem organ failure in 3 . The in-hospital mortality tended to be greater in those with AEF than in those with $\mathrm{ABF}(75 \%$ vs $50 \%, P=.44)$. No statistically significant differences were found in in-hospital mortality between primary and secondary fistulas $(66.7 \%$ vs $37.5 \%, P=.33)$. The risk factors for in-hospital mortality were hemodynamic instability on admission $(P=.02)$, sepsis $(P=.04)$, and nonoperative management $(P<.001)$.

After hospital discharge, clinical and imaging follow-up data were available for all surviving patients at a median follow-up of $52.1 \pm 62.4$ months. Overall survival estimated using the Kaplan-Meier method, including early mortality, was $37.8 \%$ at 1 year, $33.6 \%$ at 5 years, and $25.2 \%$ at 10 years. Survival for those with ABFs was $49.4 \%$ at 1 year, $43.2 \%$ at 5 years, and $32.4 \%$ at 10 years (Figure 1). Survival for those with AEFs was $12.5 \%$ at 1 and 5 years; none of these patients had reached the 10-year follow-up point at their latest follow-up visit (Figure 1). A trend was seen toward greater long-term survival in the ABF group (log-rank test, $P=.18$; Figure 1).

The overall long-term survival for the surgical patients at 1 and 5 years was $66 \%$ and $58.7 \%$, respectively. However, those patients who had undergone open repair had an actuarial survival of $85.7 \%$ at 1 and 5 years compared with long-term survival in the TEVAR group of $50 \%$ at 1 year and $33.3 \%$ at 5 years $(P=.04$; Figure 2$)$.

Better long-term survival was recorded for those patients who had presented with a secondary fistula, with 1 - and 5year survival of $62.5 \%$ compared with $26.7 \%$ and $20 \%$ for those who had presented with in a primary fistula, respectively $(P=.08)$.

Regarding the etiology of the aortic fistulas, statistically significant differences were found in long-term survival (log-rank test, $P=.002$ ). Patients with post-traumatic ABFs or AEFs had the best long-term survival $(100 \%$ at 1 and 5 years of follow-up, with only 1 late non-aortic-related death). In contrast, the worst prognosis was found among patients with fistula with an infectious origin, because none of 


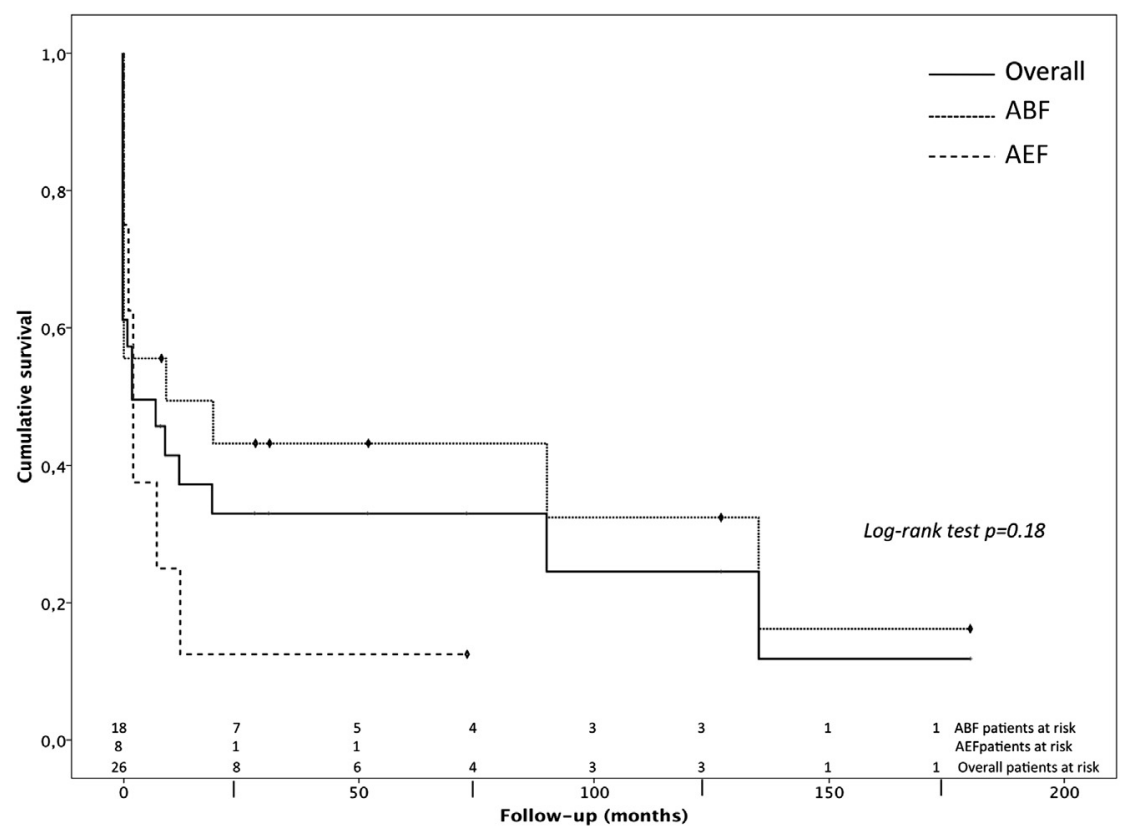

FIGURE 1. Cumulative survival for all aortic fistulas $(\mathrm{n}=26)$, aortobronchial fistulas $(A B F)$, and aortoesophageal fistulas $(A E F s)$. Better survival was seen for those with ABFs; however, this difference did not reach statistical significance. No deaths occurred after 3 months.

them survived until hospital discharge. Patients with fistulas due to malignancies had the second worst outcome, with survival of $25 \%$ at 1 year; no patients had survived to 2 years of follow-up owing to the prognosis of their associated malignancy.
None of the 13 initial survivors developed any aorticrelated complications after hospital discharge. Three late deaths occurred among the initial survivors. A 59-year-old man, who had undergone open surgical repair of a primary $\mathrm{ABF}$ due to a thoracic descending aorta aneurysm, died of

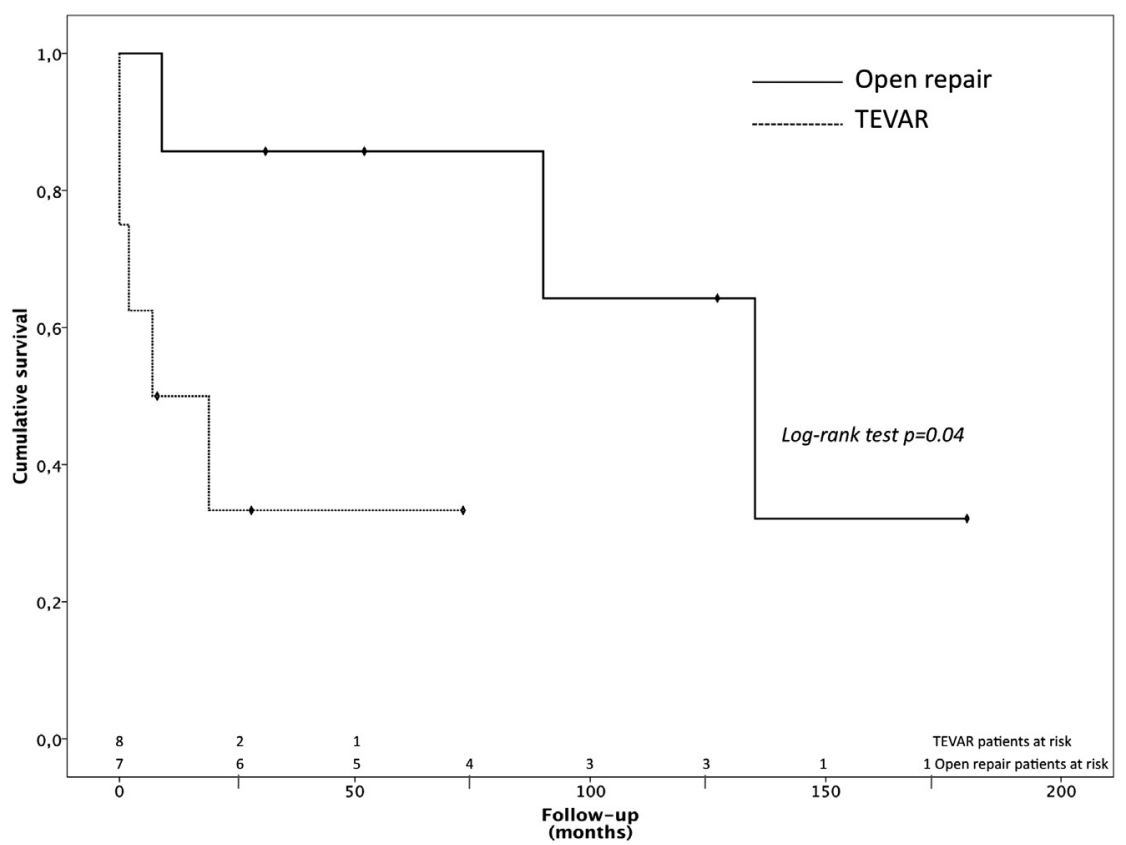

FIGURE 2. Survival stratified by surgical management type. The patients who had undergone open repair $(\mathrm{n}=7)$ had greater long-term survival than those who had undergone thoracic endovascular aortic repair $(T E V A R)(\mathrm{n}=8 ; P=.04)$. The median follow-up of the surviving patients was 31 months (range, 2-180; interquartile range, 100). 
myocardial infarction 10 years later. A 72-year-old man died of stroke 7 years after open repair of a secondary ABF. The third late death resulted from brain metastasis in a 52-yearold man who had previously undergone TEVAR for an AEF caused by squamous cell esophageal cancer.

\section{DISCUSSION}

Despite either open or endovascular initial successful management of aortic fistulas, preventing the patient's death by exsanguination, the results of the present series have demonstrated that the mid- and long-term outcomes are ultimately dependent on the etiology of the fistula. Therefore, failure to treat the underlying cause will entail a poor midterm outcome.

Contrast-enhanced CT, especially multidetector CT, has been demonstrated to be a remarkably valuable diagnostic tool for helping in the diagnosis of aortic fistulas. ${ }^{11-14}$ In a review of the published data, MacIntosh and colleagues ${ }^{17}$ found a pseudoaneurysm at the fistula site in $73 \%$ of 63 cases of ABF. Pseudoaneurysms can result from local infection or mechanical stress on the anastomosis or graft wall that causes tight adherence and pressure necrosis of the bronchopulmonary or esophageal tissue. ${ }^{17}$ We had similar results, finding an aortic pseudoaneurysm bulge at the site of the fistula in 12 patients $(50 \%)$.

Although hemorrhage of the aortic wall and pseudoaneurysm bulge were the most common radiologic findings in our series, the presence of either active contrast extravasation or ectopic gas was associated with a worse inhospital prognosis and was present only in those with AEF. The presence of periaortic or ectopic gas was associated with in-hospital mortality $(P=.04)$.

In the published data, in-hospital mortality after open surgery for $\mathrm{ABF}$ has been $15 \%$ to $25 \%{ }^{17-21}$ but tended to be even greater in those with AEF. ${ }^{1}$ The most frequently used approach for open AEF repair has been left thoracotomy, followed by aortic replacement with a prosthetic $^{17,18,20-22}$ or cryopreserved ${ }^{19,23}$ homograft or extraanatomic bypass in the case of severe mediastinal sepsis. ${ }^{20}$

In contrast, the 30-day mortality rate after $\mathrm{ABF}$ and $\mathrm{AEF}$ endovascular repair has been reported to be $28 \%$ to $45 \%$. ${ }^{8,9}$ Our results are comparable to those reported by other investigators regarding surgical treatment of thoracic aortic fistulas. ${ }^{8,9,21,23}$ In our series, the in-hospital mortality in patients undergoing open repair was slightly lower than that in the patients undergoing TEVAR; yet, that difference was not statistically significant. However, TEVAR has been performed on significantly older patients whose expected in-hospital mortality tended to be higher, as determined by the logistic EuroSCORE. Of the 7 patients who underwent TEVAR, 5 had been considered unfit for open surgical repair because of their high surgical risk, comorbidities, and/or advanced age. Furthermore, only the TEVAR group included those with aortic fistulas caused by infection or malignancy. This is the underlying rationale for the greater in-hospital mortality and lower actuarial survival observed among those patients who had undergone endovascular repair.

The incidence of $\mathrm{ABF}$ and $\mathrm{AEF}$ as a complication of previous TEVAR ranges from $2 \%$ to $3 \%$. Eggebrecht and colleagues $^{2}$ reported an incidence of AEF after TEVAR of $1.9 \%$ and confirmed that all patients had died of fatal repeat bleeding or mediastinitis. Jonker and colleagues ${ }^{8}$ published a series of 11 aortic fistulas, with 2 cases secondary to TEVAR (18.8\%). More recently, Canaud and colleagues ${ }^{24}$ reported an incidence of aortic fistula as a complication of TEVAR of $2.9 \%$ in a cohort of 236 patients. In our series, 1 case of $\mathrm{ABF}$ and 1 of AEF $(7.7 \%)$ were secondary to TEVAR. The patient sustaining an ABF was successfully treated with a second TEVAR; however, the patient with an AEF died of septic shock.

A medical conservative approach for those patients deemed nonsurgical candidates led to $100 \%$ in-hospital mortality in our series. This finding is similar to that published by other investigators, ${ }^{20,25}$ who reported a fatal outcome for those patients approached conservatively. We found that nonoperative management is strongly related to in-hospital mortality $(P<.001)$, as well as other factors as hemodynamic instability on admission $(P=.02)$ and sepsis $(P=.04)$.

Our results have highlighted that the etiology of the fistula is of paramount importance in determining patients' prognosis. In our series, all the patients with an aortic fistula with an infectious cause died during hospitalization, and those with an underlying malignancy as the main cause also had a poor mid-term prognosis. In the published data, in-hospital mortality for those with aortic fistulas secondary to mycotic aneurysms or graft infections ranged from $25 \%$ to $60 \% .^{4,8,26,27}$ In contrast, those caused by esophageal or lung malignancies were associated with a mortality close to $30 \%$. $^{9,27,28}$

In our series, post-traumatic fistulas showed great longterm survival because, in those cases, aortic surgery alone was curative. Those patients and those with fistulas caused by ingestion of a foreign body or atherosclerotic aortic pathology ${ }^{4,7-9}$ are the ideal candidates for endovascular treatment. However, caution must be stressed because, although the immediate and mid-term outcomes of TEVAR have been encouraging, ${ }^{8,9}$ the major concern is the durability of this approach in the setting of a contaminated milieu in the vicinity of foreign material. Despite appropriate surgical treatment, most patients remain at high risk of infectious complications, which were, unquestionably, the most frequent cause of in-hospital death in our series (7 patients). Other investigators have previously underlined the importance of controlling infectious complications after hemodynamically stabilizing the patient. ${ }^{8}$ TEVAR can effectively serve as a bridge to definitive open surgery in 
emergency cases of aortic fistulas, especially in those patients severely compromised on hospital admission. ${ }^{8}$

In a multicenter study of 25 patients with $\mathrm{ABF}$ and/or $\mathrm{AEF},{ }^{9}$ the investigators reported that of the 18 initial survivors, $6(33 \%)$ developed recurrent sepsis and/or hemorrhagic complications, resulting, in all cases, in death or reintervention. More recently, Canaud and colleagues ${ }^{4}$ published a review of the mid-term results of TEVAR in patients with ABFs. They identified 134 patients with ABF who had been treated with TEVAR. Recurrence of the ABF developed in 14 patients $(11 \%)$, with a fatal outcome in $50 \%$. In our series, none of the 15 survivors from hospital discharge developed aortic-related complications, including recurrent sepsis.

\section{Study Limitations}

The present study had the limitations inherent to any retrospective study. Although the patient population reflected the wide spectrum seen in clinical practice, it might have lacked sufficient statistical power to determine with confidence clinically important differences. Future studies should incorporate data from a larger number of patients acquired during a longer follow-up period to make definitive conclusions on the effectiveness of, and indications for, different surgical strategies.

\section{CONCLUSIONS}

The results of the present series have demonstrated that mid- and long-term outcomes are ultimately dependent on the etiology of the fistula. Therefore, failure to treat the underlying cause will entail a poor mid-term outcome. Both open and endovascular management of aortic fistula can prevent death by exsanguination. TEVAR seems an attractive alternative for high-risk patients, especially as a bailout or bridging procedure. However, the Achilles heel of aortic fistula management remains the difficulty in controlling the associated infection. Prolonged antibiotic therapy and lifelong surveillance seem crucial for these patients, regardless of the symptoms or clinical signs of sepsis.

\section{References}

1. von Segesser LK, Tkebuchava T, Niederhauser U, Künzli A, Lachat M, Genoni M, et al. Aortobronchial and aortoesophageal fistulae as risk factors in surgery of descending thoracic aortic aneurysms. Eur J Cardiothorac Surg. 1997;12:195-201.

2. Eggebrecht H, Mehta RH, Dechene A, Tsagakis K, Kühl H, Huptas S, et al. Aortoesophageal fistula after thoracic aortic stent-graft placement: a rare but catastrophic complication of a novel emerging technique. JACC Cardiovasc Interv. 2009;2:570-6.

3. Isasti G, Gomez-Doblas JJ, Olalla E. Aortoesophageal fistula: an uncommon complication after stent-graft repair of an aortic thoracic aneurysm. Interact Cardiovasc Thorac Surg. 2009;9:683-4.

4. Canaud L, Ozdemir BA, Bahia S, Hinchliffe R, Loftus I, Thompson M. Thoracic endovascular aortic repair for aortobronchial fistula. Ann Thorac Surg. 2013;96:
5. Bockler D, Schumacher H, Schwarzbach M, Ockert S, Rotert H, Allenberg JR. Endoluminal stent-graft repair of aortobronchial fistulas: bridging or definitive long-term solution? J Endovasc Ther. 2004;11:41-8.

6. Czerny M, Zimpfer D, Fleck T, Gottardi R, Cejna M, Schoder M, et al. Successful treatment of an aortoesophageal fistula after emergency endovascular thoracic aortic stent-graft placement. Ann Thorac Surg. 2005;80:1117-20.

7. Wheatley GH III, Nunez A, Preventza O, Ramajah VG, Rodriguez-Lopez JA, Williams J, et al. Have we gone too far? Endovascular stent-graft repair of aortobronchial fistulas. J Thorac Cardiovasc Surg. 2007;133:1277-85.

8. Jonker FH, Heijmen R, Trimarchi S, Verhagen HJ, Moll FL, Muhs BE. Acute management of aortobronchial and aortoesophageal fistulas using thoracic endovascular aortic repair. J Vasc Surg. 2009;50:999-1004.

9. Chiesa R, Melissano G, Marone EM, Marrocco-Trischitta MM, Kahlberg A. Aorto-oesophageal and aortobronchial fistulae following thoracic endovascular aortic repair: a national survey. Eur J Vasc Endovasc Surg. 2010;39:273-9.

10. von Elm E, Altman DG, Egger M, Pocock SJ, Gotzsche PC, Vandenbroucke JP. Strengthening the reporting of observational studies in epidemiology (STROBE) statement: guidelines for reporting observational studies. BMJ. 2007;335:806-8.

11. Hagspiel KD, Turba UC, Bozlar U, Harthun NL, Cherry KJ, Ahmed H, et al. Diagnosis of aortoenteric fistulas with CT angiography. J Vasc Interv Radiol. 2007; 18:497-504.

12. Pinilla I, Bret M, Cuesta E, Borches D, Oliver JM, Gomez-Leon N. Role of computed tomography and magnetic resonance imaging in aortobronchial fistula diagnosis following aortic coarctation reparative surgery: report of two cases. $J$ Cardiovasc Surg (Torino). 2006;47:221-7.

13. Urschel JD. The diagnostic importance of computed tomography in aortobronchial fistula-a case report. Angiology. 1993;44:817-9.

14. Foster CL, Kalbhen CL, Demos TC, Lonchyna VA. Aortobronchial fistula occurring after coarctation repair: findings on aortography, helical CT, and CT angiography. AJR Am J Roentgenol. 1998;171:401-2.

15. Mosquera VX, Herrera JM, Marini M, Estevez F, Cao I, Gulías D, et al. Mid-term results of thoracic endovascular aortic repair in surgical high-risk. Interact Cardiovasc Thorac Surg. 2009;9:61-5.

16. Glantz SA. It is all in the numbers. J Am Coll Cardiol. 1993;21:835-7.

17. MacIntosh EL, Parrott JC, Unruh HW. Fistulas between the aorta and tracheobronchial tree. Ann Thorac Surg. 1991;51:515-9.

18. Carter R, Mulder GA, Snyder EN Jr, Brewer LA III. Aortoesophageal fistula. Am J Surg. 1978;136:26-30.

19. Vogt PR, Pfammatter T, Schlumpf R, Genoni M, Künzli A, Candinas D, et al. In situ repair of aortobronchial, aortoesophageal, and aortoenteric fistulae with cryopreserved aortic homografts. J Vasc Surg. 1997;26:11-7.

20. Piciche M, De Paulis R, Fabbri A, Chiariello L. Postoperative aortic fistulas into the airways: etiology, pathogenesis, presentation, diagnosis, and management. Ann Thorac Surg. 2003;75:1998-2006.

21. Eren E, Keles C, Toker ME, Ersahin S, Erentug V, Guler M, et al. Surgical treatment of aortobronchial and aortoesophageal fistulae due to thoracic aortic aneurysm. Tex Heart Inst J. 2005;32:522-8.

22. Reardon MJ, Brewer RJ, LeMaire SA, Baldwin JC, Safi HJ. Surgical management of primary aortoesophageal fistula secondary to thoracic aneurysm. Ann Thorac Surg. 2000;69:967-70.

23. Saito A, Motomura N, Hattori O, Kinoshita O, Shimada S, Saiki Y, et al. Outcome of surgical repair of aorto-eosophageal fistulas with cryopreserved aortic allografts. Interact Cardiovasc Thorac Surg. 2012;14:532-7.

24. Canaud L, Alric P, Gandet T, Ozdemir BA, Albat B, Marty-Ane C. Open surgical secondary procedures after thoracic endovascular aortic repair. Eur J Vasc Endovasc Surg. 2013;46:667-74.

25. Liu SF, Chen YC, Lin MC, Kao CL. Thoracic aortic aneurysm with aortobronchial fistula: a thirteen-year experience. Heart Lung. 2004;33:119-23.

26. Kritpracha B, Premprabha D, Sungsiri J, Tantarattanapong W, Rookkapan S, Juntarapatin P. Endovascular therapy for infected aortic aneurysms. J Vasc Surg. 2011;54:1259-65; discussion 65.

27. Murphy EH, Szeto WY, Herdrich BJ, Jackson BM, Wang GJ, Bavaria JA, et al. The management of endograft infections following endovascular thoracic and abdominal aneurysm repair. J Vasc Surg. 2013;58:1179-85.

28. Konig AM, Hofmann BT, Groth S, Izbicki JR. [Emergency interventions for perforation and bleeding in esophageal cancer patients]. Chirurg. 2012;83: $722-5$. 


\section{SELECTION CRITERIA}

The selection criteria for open or endovascular treatment was consistent among all the surgeons addressing thoracic aortic disease and was in accordance with the institutional protocol. The selection criteria were the patients' hemodynamic stability, comorbidities affecting life expectancy and quality of life, and factors determining technical feasibility.
The criteria for the primary intended treatment were not consistent during the observation period of 15 years and were modified by the incorporation of TEVAR using a modern risk-benefit evaluation and critical assessment of comorbidity status. Emergency ( $<24$-hour) endovascular aortic repair was available at our institution starting in January 2003 owing to the need for an in-hospital stock of thoracic aortic endografts.

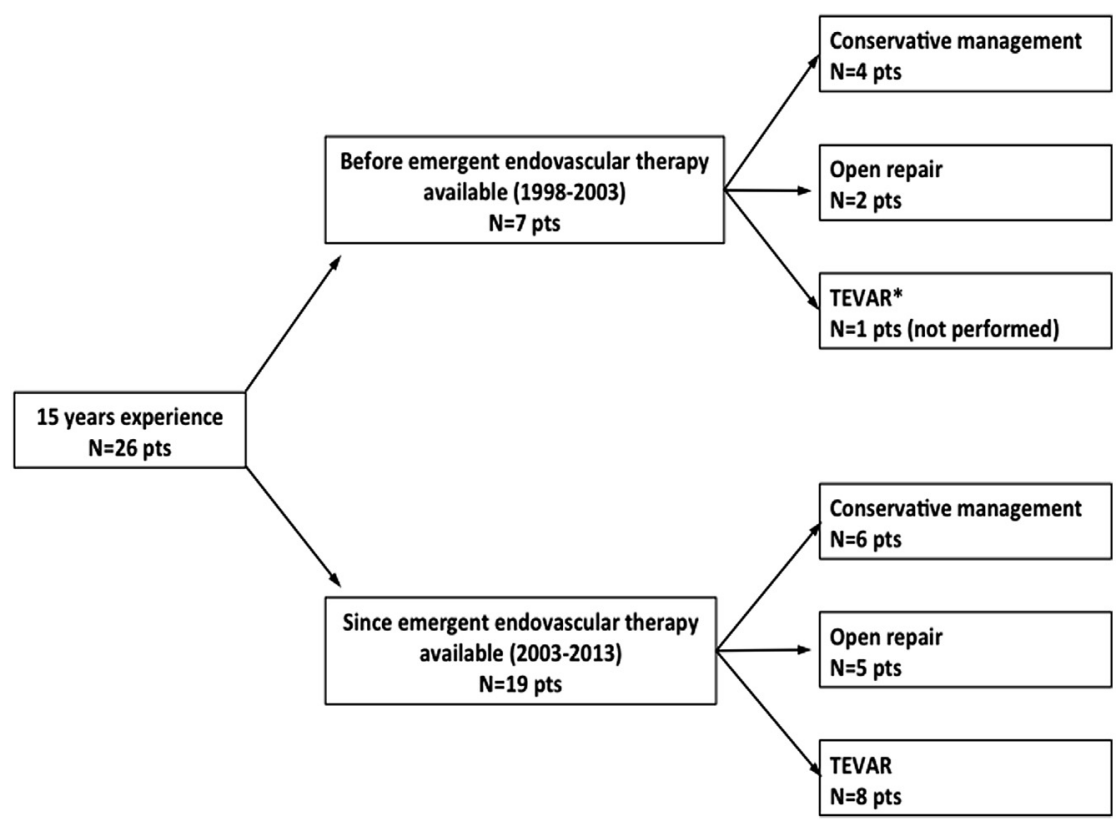

FIGURE E1. The flowchart depicts the modification in patient treatment since the incorporation of emergency aortic endografting at our institution. In the 1998 to 2003 period, 1 patient had an aortoesophageal fistulas (AEF), whose primary intended treatment was urgent thoracic endovascular aortic repair (TEVAR), but who had died waiting for the arrival of an appropriate size thoracic aortic stent-graft. 
TABLE E1. Isolated microorganisms and antibiotic therapies

Blood culture finding

Staphylococcus aureus

Staphylococcus aureus

Staphylococcus aureus

Staphylococcus aureus

Staphylococcus epidermidis

Staphylococcus epidermidis

Escherichia coli

Escherichia coli

Aspergillus fumigatus
Antibiotic used

Daptomycin $6 \mathrm{mg} / \mathrm{kg}$ IV every $24 \mathrm{~h}$

Daptomycin $6 \mathrm{mg} / \mathrm{kg}$ IV every $24 \mathrm{~h}$

Vancomycin $1 \mathrm{~g}$ every $12 \mathrm{~h}$

Vancomycin $1 \mathrm{~g}$ every $12 \mathrm{~h}$

Meropenem $1 \mathrm{~g}$ IV every $8 \mathrm{~h}$

Linezolid $600 \mathrm{mg}$ IV

every $12 \mathrm{~h}$

Vancomycin $1 \mathrm{~g}$ every $12 \mathrm{~h}$

Gentamicin $1 \mathrm{mg} / \mathrm{kg}$ IV

every $8 \mathrm{~h}$

Imipenem-cilastatin $500 \mathrm{mg}$ IV every $6 \mathrm{~h}$

Imipenem-cilastatin $500 \mathrm{mg}$ IV every $6 \mathrm{~h}$

Amphotericin B 250 mg IV every $24 \mathrm{~h}$

Caspofungin $40 \mathrm{mg}$ IV every $24 \mathrm{~h}$

Lifelong treatment with oral suppressive antibiotics was not performed in any case, and antibiotic treatment was discontinued if no clinical, bacteriologic, or radiologic evidence was found of ongoing sepsis. Our policy for antibiotic treatment involved $\geq 4$ weeks of periprocedural intravenous antibiotics followed by case-specific administration of oral suppressive antibiotics according to the clinical and laboratory parameters of infection. However, our protocol for these patients has been highly individualized. $I V$, Intravenously. 